\title{
R. delemar'IN ASİT FOSFATAZ ÜRETİMİ ve Zn(II) BİYOBİRİKİMİNİN CEVAP YÜZEY YÖNTEMİ KULLANARAK OPTİMİZE EDİLMESİ
}

\author{
Mehtap Erşan, Ünsal Açıkel \\ Cumhuriyet Üniversitesi, Kimya Mühendisliği Bölümü, Sivas, Turkey \\ mersan@cumhuriyet.edu.tr, $\underline{\text { uacikel@cumhurivet.edu.tr }}$
}

(Geliş/Received: 08.05.2013; Kabul/Accepted: 05.12.2013)

ÖZET

$R$. delemar' in asit fosfataz aktivitesi, $\mathrm{Zn}(\mathrm{II})$ biyobirikimi ve üremesi, $\mathrm{pH}$, sıcaklık ve başlangıç metal iyonu konsantrasyonunun fonksiyonu olarak araştırıldı. Deney tasarımı Cevap Yüzey Yöntemi (CYY) ve BoxBehnken tasarımına göre yapıldı. Önerilen matematiksel modeller varyans analizi (ANNOVA) istatistiksel yöntemi ile değerlendirilmiştir. Asit fosfataz aktivitesi için doğrusal, mikroorganizma derişimi ve $\mathrm{Zn}$ (II) biyobirikimi için kuadratik eşitliğe tam bir uyum gözlenmiştir. $R$. delemar' in üremesi asit fosfataz üretimi ve $\mathrm{Zn}$ (II) biyobirikimi için optimum $\mathrm{pH}$ 5,03, sıcaklık $31,82{ }^{\circ} \mathrm{C}$ ve başlangıç $\mathrm{Zn}(\mathrm{II})$ iyonu konsantrasyonu 30,15 $\mathrm{mg} / \mathrm{L}$ olarak bulunmuştur. Bu koşullarda elde edilen maksimum asit fosfataz aktivitesi 794,098 $\mu \mathrm{mol} / \mathrm{L}-\mathrm{dak}$, mikroorganizma konsantrasyonu 3,203 g/L ve biyobiriktirilen Zn(II) miktarı 17,62 mg/L olarak bulunmuştur. Deney doğrulama deneyi yapılarak sonuçların duyarlılığı ve geçerliliği gösterilmiştir.

Anahtar Kelimeler: Asit fosfataz, R. delemar, biyobirikim, Zn(II), Cevap yüzey yöntemi (CYY)

\section{OPTIMIZATION OF ACID PHOSPHATASE PRODUCTION AND ZN(II) BIOACCUMULATION by $R$. delemar USING RESPONSE SURFACE METHOD}

\begin{abstract}
Acid phosphatase activity, $\mathrm{Zn}$ (II) bioaccumulation and growth of $R$. delemar were investigated as a function of $\mathrm{pH}$, temperature and initial $\mathrm{Zn}(\mathrm{II})$ ion concentration. Experimental design was performed by response surface method (RSM) and Box-Behnken design. The proposed mathematical models were evaluated by analysis of variance (ANNOVA) statistically method. The best fit for acid phosphatase activity was obtained by linear model, the $\mathrm{Zn}$ (II) bioaccumulation and microorganism growth were characterized by quadratic equations. The optimum conditions for acid phosphatase activity, $\mathrm{Zn}$ (II) bioaccumulation and growth of R. delemar were found to be $\mathrm{pH} 5,03,31,82{ }^{\circ} \mathrm{C}$ and an initial $\mathrm{Zn}$ (II) ion concentration of $30,15 \mathrm{mg} / \mathrm{L}$. At these conditions the maksimum acid phosphatase activity $\mathrm{Zn}$ (II) bioaccumulation and microorganism concentration were determined as 794,098 mmol / L-min, 17,62 $\mathrm{mg} / \mathrm{L}$ and 3,2038 g / L respectively. To test sensivity and validity of the optimum conditions the validation experiments were performed.
\end{abstract}

Keywords: Acid phosphatase, R. delemar, bioaccumulation, Zn(II), Response surface methodology

\section{GİRIŞ (INTRODUCTION)}

Fosfatazlar fosfomonoesterazlardır ve çeşitli fosfat esterlerinin, C-O-P bağlarının hidrolizini katalizlerler. Ayrıca tıpta çeşitli hastalıkların tanı ve tedavisinde kullanılmaktadır. pH değerlerine göre asit yada alkali fosfataz olarak sınıflandırılırlar. Bu enzimler doğal ortamda oluşur, hayvan dokuları, bitkiler ve mikroorganizmalarda bulunur. Çeşitli mikroorganiz- malar tarafindan üretilen bu enzim son yıllarda yapılan bazı araştırmalara konu olmuştur. Lactobacillus plantarum DPC2739 isimli bakterinin ürettiği dış hücresel asit fosfataz incelenmiş, optimum üretim şartları $40{ }^{0} \mathrm{C}$ sicaklık ve pH 3,5-5 aralığında bulunmuştur [1]. Asit fosfataz ürettiği bilinen diğer mikroorganizmalar; Saccharomyces cerevisiae [2], Neurospora crassa [3], Euglena gracilis [4] ve 
Rhizopus delemar 'dır (R. delemar). Bu çalışmada asit fosfataz kaynağı olarak, etkili ağır metal biyosorbenti olarak bilinen $R$. delemar kullanılmıştır [5]. Ağır metal iyonlarının mikroorganizmalar üzerine biyosorpsiyonu incelendiginde, kullanılan mikroorganizmanın hücre yapısına baglı olarak degisik mekanizmaların etkili oldugu görülmektedir [6]. Ağır metal giderim prosesleri iki basamakatan oluşmaktadır.

i-) Metobolizmaya bağlı giderim (biyobirikim): Metabolik hareketlerle birlikte hücre içinde metal iyonlarının biyobirikimidir. Enerji gerektiren bir prosestir.

ii-) Metabolizmadan bağımsız giderim (pasif metal giderimi, biyosorpsiyon):

Ölü mikroorganizmalarla yapılan adsorpsiyon işlemi genellikle biyosorpsiyon olarak tanımlanmaktadır [7]. Biyosorpsiyonda kimyasal adsorpsiyon, iyon değişimi, elektrostatik çekim kuvvetleri, kompleksleşme gibi birçok mekanizmanın tek başına veye birlikte rol oynadığı düşünülmektedir. $\mathrm{Bu}$ çalışmada canlı R. delemar hücreleri ile metal biyobirikimi, hücreye bağlı metal fosfat olarak ağır metallerle çöken, inorganik fosfatı serbest bırakan hücreye bağlı fosfataz enzimi aracılığı ile gerçekleştirilmektedir. Asit fosfataz uygun organik veya inorganik fosfat kaynağından $\mathrm{HPO}_{4}^{-2}$ 'yi serbest bırakır. Bu fonksiyonu üreme periyodunu tamamlamış ve/veya tutuklanmış mikroorganizma hücreleri de gösterebilir. Hidrojen fosfat, $\mathrm{M}^{+2}$ ile stokiyometrik olarak çökerek hücre yüzeyine $\mathrm{MHPO}_{4}$ oluşturmak üzere sıkıca bağlanır. Bu mekanizma ile metal içeren çözeltilerde $\mathrm{Cd}, \mathrm{U}, \mathrm{Sr}$ ve $\mathrm{Pb}$ iyonlarının Citrobacter $s p$ grubu bakteriyel hücreler kullanılarak biyobirikiminin gerçekleştiği rapor edilmiştir [8].

Bu çalışmada $R$.delemar' In ürettiğ $i$ asit fosfataz aracılığı ile $\mathrm{Zn}(\mathrm{II})$ biyobirikiminin gerçekleştiği optimum koşulların bulunması amaçlanmaktadır. Klasik yöntemlerle optimum deney koşullarının bulunması için çok sayıda deney yapmak gereklidir. Elde edilen sonuçlarla ise optimum deney koşulları üzerinde deney değişkenlerinin birbirleri üzerine olan etkilerini görmek mümkün değildir. $\mathrm{Bu}$ tür kısıtlamaları ortadan kaldırmak amaci ile Cevap Yüzey Yöntemi (CYY) ve Box-Behnken deney tasarımı kullanılarak, pH, sıcaklık ve başlangıç metal iyonu konsantrasyonu bağlı olarak, asid fosfataz aktivitesi, $R$. delemar üremesi ve $\mathrm{Zn}$ (II) biyobirikimi optimize edilmiştir. Elde edilen matematiksel modeller, ANNOVA (Analysis of variance) istatistiksel yöntemi ile değerlendirilmiş, modellerin doğruluğu ve geçerliliği tartışılmıştır [9].

\section{MATERYAL ve METOD (MATERIAL and METHOD)}

2.1. R. delemar' In Asit Fosfataz Enzimi Aktivitesi ve Besin Ortamlarının Hazırlanması (Acid Phosphatase Activity of $R$. delemar and Growth Medium Preparation)

Asit fosfataz üretiminde kullanılan aşı ortamı ve asit fosfataz üretiminde kullanılan fermantasyon ortamı hazırlanmış ve $100 \mathrm{ml}$ çalışma hacmine sahip reaktörlerde fermentasyon gerçekleştirilmiştir. Aşılama için besin ortamı içeren erlenler, 150 devir/dak hızında, $30{ }^{\circ} \mathrm{C}$ sicaklıkta ve 24 saat orbital çalkalayıcıda karıştırılmıştır. Ortam pH' 1, mikroorganizmanın asit fosfataz enzimi üretmesi için en uygun pH değeri olan 4,8'e ayarlanmıştır [10].

\subsection{Analitik Ölçüm Yöntemleri (Analytical Measurement Methods)}

Belirli zaman aralıklarında fermantasyon ortamlarından steril olarak alınan örnekler filtrasyon ve/veya santrifüjleme işleminden geçirilmiş, sıv1 k1sım metal iyonları ve enzim aktivitesinin tayininde, dipte çökelen kısım veya filtrasyon kağıdının üzerinde kalan kısım ise mikroorganizma konsantrasyonunun bulunmasında kullanılmıştır. Alınan örnekteki yaş mikroorganizma konsantrasyonu $\mathrm{g} / \mathrm{L}$ cinsinden spektrofotometrik olarak $360 \mathrm{~nm}$ 'de absorbans okunarak tayin edilmiştir. Daha sonra yaş ağırlık-kuru ağırlık mikroorganizma çalışma doğrusundan yararlanarak kuru mikroorganizma konsantrasyonuna geçilmiştir.

\subsection{Asit Fosfataz Aktivitesi Tayini (Acid Phosphatase Activity Determination)}

Fosfataz aktivitesinin ölçümü için substrat olarak $p$ nitrophenyl phosphate (pNPP, Sigma 117K8210) kullanılarak önceden tanımlandığı gibi tayin edilmiştir [10] (Ac1kel ve Ersan, 2010). Fosfataz aktivitesi, 410 $\mathrm{nm}$ dalga boyunda spektrofotometrik olarak ölçülmüştür. Bir birim fosfataz aktivitesi pH 4,8 ve 37 ${ }^{\circ} \mathrm{C}$ ' de $1 \mu \mathrm{mol}$ p-nitrophenol / dak serbest birakan enzim çözeltisinin miktarı olarak tanımlanır [5].

\subsection{Metal İyonları İçeren Biyobirikim Ortamının Hazırlanması (Preperation of Bioaccumulation Medium Containinig Metal Ions)}

$\mathrm{Zn}$ (II) çözeltileri, $\mathrm{ZnSO}_{4} \cdot 5 \mathrm{H}_{2} \mathrm{O}$ kristallerinin damitık suda çözülmesi ile elde edilen $1,0 \mathrm{~g} / \mathrm{L}$ metal iyonu içeren stok çözeltilerden seyreltilerek hazırlanmıştır. Fermentasyon ortamlarının $\mathrm{pH}$ değeri $1 \mathrm{~mol} / \mathrm{L}$ konsantrasyonunda hazırlanan $\mathrm{HNO}_{3}$ stok çözeltisi kullanılarak ayarlanmıştır. 


\subsection{Biyobirikim Deneyleri (Bioaccumulation Experiments)}

Biyobirikim deneyleri orbital çalkalayıcıda $30{ }^{\circ} \mathrm{C}$ sıcaklıkta 150 devir/dak karıştırma hızında 48 saat süreyle yapılmıştır. Optimizasyon deneylerinde, $R$. delemar' in maksimum asid fosfataz aktivitesi gösterdiği saptanan, üstel üreme evresinin sonundaki hücreler kullanılmıştır. Fermentasyon ortamından alınan $5 \mathrm{ml}$ hacmindeki örnek $6030 \mathrm{x}$ g' de 5 dakika santrifüjlenmiş ve ortamdaki serbest $\mathrm{Zn}$ (II), 213,9 nm' de atomik absorbsiyon spektrofotometresinde ölçülmüştür.

Burada $x_{i}$ bağımsız bir değişkenin kodlanmış değeridir, $X_{i}$ bağımsız bir değişkenin gerçek değeridir, $X_{0}$ merkez noktada bağımsız bir değişkenin gerçek değeridir, $\Delta X_{i}$ basamak değişim değeridir. Box-Benkhen tasarımı kullanılarak araştırılan $\mathrm{pH}$, sıcaklık ve başlangıç $\mathrm{Zn}(\mathrm{II})$ iyonu bağımsız değişkenlerinin aralığ 1 ve düzeyleri Tablo 1.' de gösterilmektedir. Söz konusu bağımsız değişkenlerin aralıkları, bir deney setinde bir parametrenin değerinin değiştirildiği diğer parametrelerin değerlerinin sabit tutulduğu deney sistemlerinde belirlenmiştir. Asit fosfataz aktivitesi, biyobiriktirilen $\mathrm{Zn}$ (II) iyonu konsantrasyonu ve mikroorganizma konsantrasyonu bağımlı değişken veya tasarım deneylerinin cevabı olarak alınmaktadır. Sistemin davranışı aşağıdaki kuadratik eşitlik tarafından ifade edilir:

\subsection{Deney Sisteminin Matematiksel Modellenmesi (Metematical Modelling of Experimental System)}

\section{Yüzey Cevap Yöntemi (Response Surface Methodology)}

Asit fosfataz aktivitesi, Zn(II) biyobirikimi ve mikroorganizma derişiminin optimizasyonu için merkezi bileşke tasarımı (Acid phosphatase activity, Zn (II) bioaccumulation and central composite design for optimization of microorganism concentration)

R. delemar' in asit fosfataz enzimi üretimi ve $\mathrm{Zn}$ (II) biyobirikimi için, optimum fermentasyon koşullarının saptanması amacıyla, pH, sıcaklık ve başlangıç $\mathrm{Zn}$ (II) iyonu konsantrasyonunun etkilerini araştırmak üzere, Box-Benkhen deneysel tasarımı uygulanmıştır. İstatiksel hesaplamalar için, $\mathrm{X}_{1}$ ve $\mathrm{X}_{2}$ ile gösterilen iki bağımsız değişken, (1) numaralı eşitliğe göre kodlanmıştır:

$$
\begin{aligned}
& x_{i}=\frac{X_{i}-X_{0}}{\Delta X_{i}} \\
& Y=\beta_{0}+\sum \beta_{i} x_{i}+\sum \beta_{i i} x_{i}^{2}+\sum \beta_{i j} x_{i} x_{j}
\end{aligned}
$$

Burada Y önerilen cevap, $\beta_{0}$ ofset terimi, $\beta_{\mathrm{i}}$ doğrusal etki, $\beta_{\mathrm{ii}}$ kare etkisi ve $\beta_{\mathrm{ij}}$ ' de parametreler arasındaki karşılıklı etkileşimi gösteren katsayıdır. Her deneysel nokta iki kez tekrar edildi. Tekrar edilen değerlerin aritmetik ortalaması, Box-Benkhen tasarımında kullanıld1. Design Expert 7,0 bilgisayar programı, deneysel verilerin regresyon analizi ile Eşitlik 2' nin katsayılarının hesaplanması için kullanılmıştır.

\section{DENEYSEL SONUÇLAR ve TARTIŞMA (RESULTS and DISCUSSION)}

Klasik biyobirikim deneyleri sonucunda belirlenen en uygun $\mathrm{pH}$ ve sicaklık aralıkları dikkate alınarak, deney sisteminin yüzey cevap yöntemiyle, deneysel çalışma aralıkları, en düşük $\mathrm{pH}$ değeri olarak 4,0 en yüksek pH değeri olarak 5,5, en düşük sıcaklık değeri olarak $25{ }^{\circ} \mathrm{C}$, en yüksek sicaklık değeri olarak $36{ }^{\circ} \mathrm{C}$ seçilmiştir. Tasarım çalışmaları için düşük derişimlerde aktivator etkisi göstermesi nedeniyle ağır metal olarak Zn(II) seçilmiştir. Sisteme eklenen Zn(II) konsantrasyonu 10-50 $\mathrm{mg} / \mathrm{L}$ derişim aralığında değiştirilmiştir. $\mathrm{pH}$, sıcaklık ve başlangıç $\mathrm{Zn}(\mathrm{II})$ konsantrasyonu bağımsız değişkenlerine karşı, cevap değişkenleri, asit fosfataz aktivitesi, mikroorganizma derişimi ve metal biyobirikimi için elde edilen deneysel ve yöntem tarafindan öngörülen değerler Tablo 2' de karşılaştırılmaktadır.

3.1. R. delemar ile Maksimum Asit Fosfataz Aktivitesi Elde Etmek İçin Deney Koşullarının Belirlenmesi (Determination of Experimental Conditions for Maximum Acid Phosphatase Activity of R. delemar)

Eşitlik 3 tarafından ifade edilen model $\mathrm{pH}$, sıcaklık ve başlangıç $\mathrm{Zn}(\mathrm{II})$ derişiminin fonksiyonu olarak asit fosfataz aktivitesini göstermektedir. Elde edilen model doğrusal bir eşitliktir ve denklemi aşağıdaki gibidir.

Enzim aktivitesi $=757,73+81,08 \mathrm{x}_{1}+30,83 \mathrm{x}_{2}-$ $159,14 x_{3}$

Tablo 1. Bağımsız değişken aralıkları ve cevap değişkenleri (Level and code of independent variables)

\begin{tabular}{|c|c|c|c|c|c|}
\hline \multirow{2}{*}{ Bağımsız değişken } & \multicolumn{2}{|c|}{ Semboller } & \multicolumn{3}{c|}{ Kodlanmış düzeyler } \\
\cline { 2 - 6 } & Kodlanmamış & Kodlanmış & -1 & 0 & 1 \\
\hline $\mathrm{pH}$ & $\mathrm{X}_{1}$ & $\mathrm{x}_{1}$ & 4,00 & 4,75 & 5,50 \\
\hline $\mathrm{T}\left({ }^{0} \mathrm{C}\right)$ & $\mathrm{X}_{2}$ & $\mathrm{X}_{2}$ & 25,0 & 30,5 & 36,0 \\
\hline $\mathrm{C}_{\mathrm{Zn}, \mathrm{i}}(\mathrm{mg} / \mathrm{L})$ & $\mathrm{X}_{3}$ & $\mathrm{X}_{3}$ & 10 & 30 & 50 \\
\hline
\end{tabular}


Eşitlik 3' ün istatiksel anlamı $\mathrm{F}$ testiyle kontrol edildi. Doğrusal modelin cevap yüzeyi için varyans analizi (ANNOVA) Tablo 3.'de verilmiştir. Elde edilen sonuçların anlamlı olabilmesi için modelde "Prob>F", diye ifade edilen olasılık değerinin 0,05 ' ten küçük olması gerekir. Olasılık değerinin 0,1000 ' den büyük olduğu durumlarda tasarım cevap değişkenleri için anlamsız olur. Model F-değerinden ve çok düşük probabilite değerinden anlaşıldığı üzere, model anlamlıdır. Modelin uyum derecesi belirtme katsayısı $\mathrm{R}^{2}$ ve çoklu korelasyon katsayısı, $\mathrm{R}^{\prime}$ nin değerine bakılarak kararlaştırılır. R' nin değeri 1' e ne kadar yakınsa, deneysel ve model değerler arasındaki korelasyon o ölçüde iyidir. Asit fosfataz aktivitesi için öngörülen modelin $0,9275^{\prime}$ lik $\mathrm{R}^{2}$ değeri deneysel verilerle model tarafindan öngörülen değerlerin uyumuna işaret eder.

Tablo 2. Asit fosfataz aktivitesi, mikroorganizma konsantrasyonu ve $\mathrm{Zn}$ (II) biyobirikiminin deneysel ve model değerleri içeren Box-Behnken tasarım matriksi (Box-Behnken design matrix along with the experimental and predicted values of acid phosphatase activity, biomass concentration and $\mathrm{Zn}(\mathrm{II})$ bioaccumulation)

\begin{tabular}{|c|c|c|c|c|c|c|c|c|c|c|c|c|}
\hline \multirow{2}{*}{ SET } & \multicolumn{3}{|c|}{$\begin{array}{l}\text { Gerçek } \\
\text { Değerler }\end{array}$} & \multicolumn{3}{|c|}{$\begin{array}{l}\text { Asit Fosfataz Aktivitesi } \\
(\mu \mathrm{mol} / \mathrm{L}-\text { dak })\end{array}$} & \multicolumn{3}{|c|}{$\begin{array}{l}\text { Mikroorg. Derişimi } \\
(\mathrm{g} / \mathrm{L})\end{array}$} & \multicolumn{3}{|c|}{$\begin{array}{c}\text { Metal } \\
\text { Biyobirikimi }(\mathrm{mg} / \mathrm{L})\end{array}$} \\
\hline & $\mathrm{pH}$ & $\mathrm{T}$ & $\mathrm{C}_{\mathrm{Zn}, \mathrm{i}}$ & $\begin{array}{l}\text { Model } \\
\text { değerler }\end{array}$ & $\begin{array}{c}\text { Deneysel } \\
\text { değerler }\end{array}$ & $\%$ Hata & $\begin{array}{l}\text { Model } \\
\text { değerler }\end{array}$ & $\begin{array}{c}\text { Deneysel } \\
\text { değerler }\end{array}$ & $\%$ Hata & $\begin{array}{l}\text { Model } \\
\text { değerler }\end{array}$ & $\begin{array}{c}\text { Deneysel } \\
\text { değerler }\end{array}$ & $\%$ Hata \\
\hline 1 & 0 & 1 & 1 & 633,07 & 666,11 & $-5,21$ & 2,59 & 2,58 & 0,63 & 34,39 & 34,00 & 1,17 \\
\hline 2 & 0 & 0 & 0 & 757,87 & 746,32 & 1,52 & 3,09 & 3,10 & $-0,20$ & 16,50 & 16,66 & $-0,91$ \\
\hline 3 & 0 & 0 & 0 & 757,87 & 746,32 & 1,52 & 3,09 & 3,10 & $-0,20$ & 16,50 & 16,66 & $-0,91$ \\
\hline 4 & 0 & -1 & 1 & 572,68 & 596,13 & $-4,09$ & 2,42 & 2,42 & 0,33 & 21,56 & 21,40 & 0,79 \\
\hline 5 & -1 & 1 & 0 & 711,66 & 721,42 & $-1,37$ & 3,57 & 3,57 & 0,04 & 20,79 & 20,2 & 2,95 \\
\hline 6 & 0 & 0 & 0 & 757,87 & 785,32 & $-3,62$ & 3,09 & 3,10 & $-0,20$ & 16,50 & 16,9 & $-2,32$ \\
\hline 7 & 1 & -1 & 0 & 804,09 & 792,31 & 1,46 & 3,02 & 3,00 & 0,81 & 12,05 & 12,3 & $-1,99$ \\
\hline 8 & -1 & 0 & 1 & 526,46 & 512,21 & 2,70 & 2,63 & 2,61 & 0,82 & 28,35 & 28,11 & 0,85 \\
\hline 9 & 0 & -1 & -1 & 882,68 & 845,00 & 4,19 & 2,73 & 2,73 & 0,21 & 3,76 & 3,96 & $-4,80$ \\
\hline 10 & 0 & 0 & 0 & 757,87 & 752,21 & 0,74 & 3,09 & 3,0 & 3,02 & 16,50 & 16,75 & $-1,45$ \\
\hline 11 & 0 & 1 & -1 & 943,07 & 912,21 & 3,27 & 3,85 & 3,84 & 0,38 & 6,69 & 6,86 & $-2,36$ \\
\hline 12 & 1 & 1 & 0 & 864,48 & 841,32 & 2,67 & 3,80 & 3,81 & $-0,06$ & 20,37 & 20,42 & $-0,21$ \\
\hline 13 & -1 & 0 & -1 & 836,46 & 836,32 & 0,017 & 2,99 & 3,00 & $-0,17$ & 5,60 & 5,93 & $-5,53$ \\
\hline 14 & 1 & 0 & 0 & 757,87 & 721,21 & 4,83 & 3,09 & 3,10 & $-0,29$ & 16,50 & 16,5 & 0,04 \\
\hline 15 & -1 & -1 & 0 & 651,27 & 661,00 & $-1,5$ & 3,06 & 3,04 & 0,89 & 13,36 & 13,21 & 1,14 \\
\hline 16 & 1 & 0 & 1 & 679,28 & 645,96 & 4,90 & 2,30 & 2,28 & 1,22 & 27,48 & 27,96 & $-1,68$ \\
\hline 17 & 1 & 0 & -1 & 989,28 & 1100 & $-11,19$ & 3,51 & 3,51 & 0,04 & 4,73 & 7,50 & $-1,08$ \\
\hline
\end{tabular}

Tablo 3. Cevap yüzeyi doğrusal eşitlik için, ortam bileşenlerinin fonksiyonu olarak asit fosfataz aktivitesinin varyans analizi (ANNOVA) (Analysis of variance (ANOVA) for the fitted quadratic polynomial model of acid phosphatase activity as a function of concentration levels of medium components)

\begin{tabular}{|c|c|c|c|c|c|c|}
\hline Kaynak & $\begin{array}{l}\text { Kareler } \\
\text { toplamı } \\
\text { (Sum of } \\
\text { squares) }\end{array}$ & DF & $\begin{array}{l}\text { Ortalamanın } \\
\text { Karesi (Mean } \\
\text { square) }\end{array}$ & F- Değeri & $\begin{array}{l}\text { Probobilite } \\
(\mathrm{P})>\mathrm{F}\end{array}$ & \\
\hline Model & $2,628.10^{5}$ & 3 & 87599,58 & 55,46 & 0,0001 & uyumlu \\
\hline $\begin{array}{l}\text { Arta kalan } \\
\text { (Residual) }\end{array}$ & 20531,86 & 13 & 1579,37 & & & \\
\hline $\begin{array}{l}\text { Uyum eksikliği } \\
\text { (Lack of fit) }\end{array}$ & 18423,91 & 9 & 2047,10 & 3,88 & 0,1021 & \\
\hline Hata (Pure eror) & 2107,95 & 4 & 526,99 & & & \\
\hline $\begin{array}{l}\text { Düzeltilmiş } \\
\text { toplam }\end{array}$ & $2,833 \cdot 10^{5}$ & 16 & & & & \\
\hline $\mathrm{R}^{2}=0,9275$ & $\mathrm{R}_{\text {Adj }}^{2}=0,9108$ & $\mathrm{R}_{\text {Pred }}^{2}=0,8564$ & $\mathrm{R}=0,9632$ & & & \\
\hline
\end{tabular}


Yüzde olarak ifade edildiğinde, $\mathrm{R}^{2}$ enzim aktivitesi için \% 92,75 toplam değişimin bağımsız değişkenlere atfedilebileceğini, toplam değişimin yanlız \% 7,25, sinin modelle ifade edilemediğini göstermektedir. $\mathrm{R}_{\text {Pred }}^{2}(0,8564), \quad \mathrm{R}_{\text {Adj }}^{2}(0,9108)$ ile iyi bir uyum içerisindedir. Eğer modelde pekçok değişken varsa ve örnek miktarı çok değilse $\mathrm{R}^{2}$ dj, $\mathrm{R}^{2}$ den belirgin şekilde küçük olabilir. Sonuç olarak bu değerlerin birbirine ve 1' e yaklaşması modelin başarısını göstermektedir.

Yeterli kesinlik (adequate precision), sinyal gürültü oranını gösterir. Sinyal gürültü oranının ise $4^{\text {' ün }}$ üstünde olması beklenir. Bu çalışmada bulunan sinyal gürültü oranı 24,922 yeterli sinyale işaret etmektedir. Uyum eksikliği (lack of fit), regresyonda içerilmeyen noktalarda deneysel kümedeki verileri göstermek için modelin başarısını ölçer. Eşitlik 3' ün regresyonundan elde edilen uyum eksikliği anlamlı değildir $(\mathrm{P}=0,1021)$. Anlamlı olmayan uyum eksikliği iyidir ve öngörülen eşitliğinin değişkenlerin değerlerinin herhangi bir kombinasyonunda asit fosfataz aktivitesini önermek için yeterli olduğunu göstermektedir. Asit fosfataz aktivitesi için doğrusal bir eşitlik elde edilmiş olması incelenen parametrelerin

birbirini

etkilemediğini göstermektedir. $R$. delemar' in asid fosfataz aktivitesi gösterdiği pH optimumu sıcaklıktan bağımsızdır. Bunun terside doğrudur. Asid fosfatazın aktivite gösterdiği sıcaklık aralığı ortam pH' ina bağlı olarak değişmez. Eşitlik 3.'ün regresyonunun grafiksel gösterimlerine cevap yüzeyleri denir. Üç boyutlu cevap yüzeyleri design expert kullanılarak elde edilmiş ve Şekiller 1-a, b ve c ile gösterilmiştir.

Grafiklerden de görüldüğü gibi ortam pH' 1 5,03' e, sıcaklık $31,82{ }^{\circ} \mathrm{C}$ ' ye ve başlangıç metal iyonu derişimi 30,15 mg/L' ye kadar arttırılmasıyla, asit fosfataz aktivitesinin 794,098 $\mu \mathrm{mol} / \mathrm{L}-$ dak' ya kadar arttığı gözlenmiştir. Daha önceki bir deney setinde bir parametrenin değerinin değiştirilip, diğerlerinin sabit tutulduğu konvansiyonel modellerle yapılan deneylerde, $R$. delemar' in ortamda $\mathrm{Cu}(\mathrm{II})$ ve $\mathrm{Ni}(\mathrm{II})$ iyonlarının varlığında $\mathrm{pH} 4,8-5,0$, sıcaklık $30-35{ }^{\circ} \mathrm{C}$ arasında asid fosfataz enzimini ürettiği gösterilmiştir. Literatürde farklı kaynaklardan elde edilen fosfataz için aktiviteyi arttırıcı ve azaltıcı farklı ortamlar ifade edilmektedir [11]. Bu çalışmada uygulanan yüzeycevap modeli ile bulunan $\mathrm{pH}$ ve sicaklık optimumları literatürle uyumludur [6].

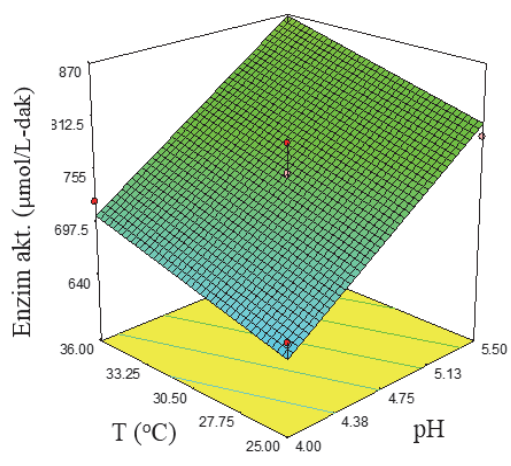

(a)

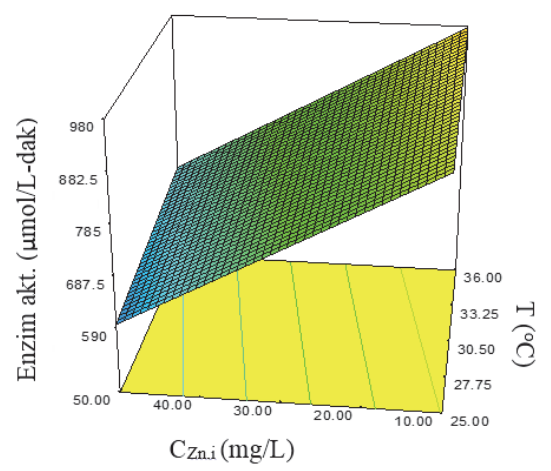

(b)

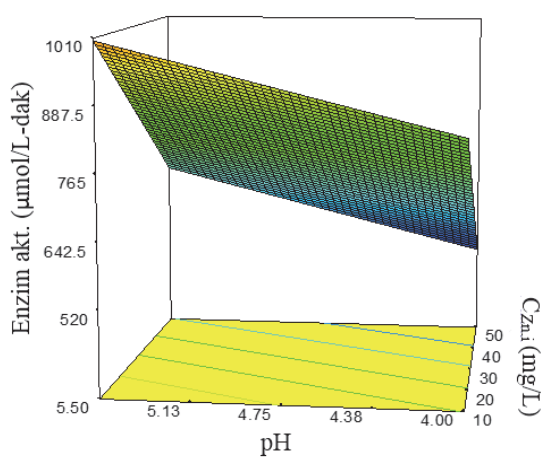

(c)

Şekil 1. (a) CYY ile, enzim aktivitesinin pH ve sıcaklıkla değişimini gösteren üç boyutlu grafiği (b) CYY ile, enzim aktivitesinin, $C_{Z n, i}$ ve sıcaklıkla değişimini gösteren üç boyutlu grafiği

(c) CYY ile, enzim aktivitesinin $\mathrm{C}_{\mathrm{Zn}, \mathrm{i}}$ ve $\mathrm{pH}$ ile değişimini gösteren üç boyutlu grafiğgi (Figure 1. (a) Response surface plot described by the model which represents the effect of $\mathrm{pH}$ and temperature and their mutual effects on acid phosphatase activity (b) Response surface plot described by the model which represents the effect of $\mathrm{C}_{\mathrm{Zn}, \mathrm{i}}$ and temperature and their mutual effects on acid phosphatase activity (c) Response surface plot described by the model which represents the effect of $\mathrm{C}_{\mathrm{Zn}, \mathrm{i}}$ and $\mathrm{pH}$ and their mutual effects on acid phosphatase activity) 
Tablo 4. Cevap yüzeyi kuadratik eşitlik için, ortam bileşenlerinin fonksiyonu olarak R. delemar' in $\mathrm{Zn}$ (II) biyobirikimi için varyans analizi (ANNOVA) ( Analysis of variance (ANOVA) for the fitted quadratic polynomial model of $\mathrm{Zn}(\mathrm{II})$ bioaccumulating as a function of concentration levels of medium components)

\begin{tabular}{|c|c|c|c|c|c|c|c|}
\hline Kaynak & $\begin{array}{l}\text { Kareler } \\
\text { toplamı } \\
\text { (Sum of } \\
\text { squares) }\end{array}$ & $\mathrm{DF}$ & $\begin{array}{l}\text { Ortalam } \\
\text { Karesi } \\
\text { square) }\end{array}$ & $\begin{array}{l}\text { nanın } \\
\text { (Mean }\end{array}$ & F- Değeri & $\begin{array}{l}\text { Probobilite } \\
(\mathrm{P})>\mathrm{F}\end{array}$ & \\
\hline Model & 1152,72 & 9 & 128,08 & & 4008,86 & $<0,0001$ & uyumlu \\
\hline $\begin{array}{l}\text { Arta kalan } \\
\text { (Residual) }\end{array}$ & 0,22 & 7 & 0,032 & & & & \\
\hline $\begin{array}{l}\text { Uyum eksikliği } \\
\text { (Lack of fit) }\end{array}$ & 0,14 & 3 & 0,046 & & 2,15 & 0,2362 & \\
\hline Hata (Pure eror) & 0,086 & 4 & 0,021 & & & & \\
\hline $\begin{array}{l}\text { Düzeltilmiş } \\
\text { toplam }\end{array}$ & 115295 & 16 & & & & & \\
\hline $\mathrm{R}^{2}=0,9998$ & $\mathrm{R}_{\mathrm{Adj}}^{2}=0,9996$ & $\mathrm{R}_{\text {Pred }}^{2}=$ & 9980 & $\mathrm{R}=0,99$ & & & \\
\hline
\end{tabular}

3.2. R. delemar' in Zn(II) Biyobirikimi İçin Deney Koşullarının Belirlenmesi (Determination of Experimental Conditions for Zn (II) Bioaccumulation of $R$. delemar)

Eşitlik 4 tarafından ifade edilen model $\mathrm{pH}$, sıcaklık ve başlangıç $\mathrm{Zn}$ (II) konsantrasyonunun fonksiyonu olarak $R$. delemar tarafindan biyobiriktirilen $\mathrm{Zn}$ (II) konsantrasyonunu göstermektedir. Elde edilen eşitlik quadratik bir eşitliktir ve denklemi aşağıdaki gibidir:

$\mathrm{Zn}$ (II) biyobirikimi $=16,69-0,25 \mathrm{x}_{1}+3,83 \mathrm{x}_{2}+11$, $24 \mathrm{x}_{3}-0,28 \mathrm{x}_{1} \mathrm{x}_{2}+0,25 \mathrm{x}_{1} \mathrm{x}_{3}+2,42 \mathrm{x}_{2} \mathrm{x}_{3}-9,510^{-3} \mathrm{x}_{1}-$ $0,15 \mathrm{x}_{2}^{2}+0,013 \mathrm{x}_{3}^{2}$

Eşitlik 4'ün istatiksel anlamı F testiyle kontrol edildi. Cevap yüzeyi quadratik eşitlik için varyans analizi (ANOVA) Tablo 4. 'de verilmiştir.

Model için F değeri 4008,65 olarak bulunmuştur. Model F değerinden ve probabilite değerininin 0,0001'den küçük olmasından modelin uyumlu olduğu anlaşılmaktadır. Zn(II) biyobirikimi için bulunan ikinci dereceden modelin $\mathrm{R}^{2}, \mathrm{R}_{\text {Adj }}^{2}, \mathrm{R}_{\text {Pred ve }}^{2}$ $\mathrm{R}(0,9989-0,9998)$ değerlerinin 1 ' e çok yakın olması deneysel değerlerle model tarafindan öngörülen değerlerin mükemmel bir uyum içerisinde olduğunu göstermektedir. Model değişkenlerinin önündeki katsayıların anlamlı olup olmadığını kontrol etmek için $\mathrm{p}$ değerleri kullanılmaktadır. Olasılık p değerlerinin 0,05 ' den küçük olması pH' in, sıcaklığın ve başlangıç $\mathrm{Zn}$ (II) konsantrasyonunun birinci dereceden etkisinin öngörülen biyobirikim modelinde anlamlı olduğunu göstermektedir. Çalışılan başlangıç $\mathrm{Zn}$ (II) derişimi aralığında, $\mathrm{pH}$ ve sıcaklığın, $\mathrm{pH}$ ve konsantrasyonun, sicaklık ve derişimin karşılıklı etkileşimlerinin biyobirikim üzerinde önemli olduğu görülmektedir. Öte yandan 0,1 ' den büyük olasılık $p$ değerleri, pH, sıcaklık ve başlangıç $\mathrm{Zn}(\mathrm{II})$ iyonu konsantrasyonunun ikinci dereceden etkilerinin anlamsız olduğunu göstermektedir. $\mathrm{Bu}$ durum $\mathrm{pH}$, sıcaklık ve başlangıç $\mathrm{Zn}(\mathrm{II})$ iyonu konsantrasyonu küçük değişimlerin Zn(II) biyobirikimini etkilemediğini göstermektedir. Eşitlik 4' ün regresyonunun grafiksel gösterimlerine cevap yüzeyleri denir. Üç boyutlu cevap yüzeyleri design expert kullanılarak elde edilmiş ve Şekil $2-\mathrm{a}, \mathrm{b}$ ve c ile gösterilmiştir. Sıcaklık ve pH'ın sırasıyla $31,82{ }^{\circ} \mathrm{C}$ ve 5,03'e arttırılmasıyla $\mathrm{Zn}$ (II) biyobirikiminin arttığ1 gözlenmiştir (Şekil 2-a). Çalışılan sıcaklık aralığında başlangıç $\mathrm{Zn}$ (II) iyon derişiminin $30,15 \mathrm{mg} / \mathrm{L}$ ' ye kadar arttırılmasıyla Zn(II) biyobirikiminin de arttığ1 gözlenmiștir (Şekil 2-b). Çalıșılan $\mathrm{pH}$ aralığında başlangıç $\mathrm{Zn}$ (II) derişiminin artmasıyla biyobiriktirilen $\mathrm{Zn}(\mathrm{II})$ iyonu derişimi neredeyse doğrusal olarak artmış ve maksimum değeri 17,622 mg/L’ ye ulaşmıştır (Şekil 2-c).

\section{3. $R$. delemar Üremesi İçin Deney Koşullarının Belirlenmesi (Determination of Experimental Conditions for Growth of $R$. delemar)}

Eşitlik 5 tarafindan verilen model $\mathrm{pH}$, sicaklık ve başlangıç $\mathrm{Zn}$ (II) konsantrasyonunun fonksiyonu olarak $R$. delemar derişimini göstermektedir. Elde edilen model 2 . dereceden bir eşitliktir ve denklemi aşağıdaki gibidir:

Mikroorganizma derişimi $=3,08+0,048 \mathrm{x}_{1}+0,33 \mathrm{x}_{2}$ $-0,40 \mathrm{x}_{3}+0,07 \mathrm{x}_{1} \mathrm{x}_{2}+0,21 \mathrm{x}_{1} \mathrm{x}_{3}-0,24 \mathrm{x}_{2} \mathrm{x}_{3}+0,12$

$x_{1}^{2}-0,16 x_{2}^{2}-0,35 x_{3}^{2}$

Eşitlik 5' in istatiksel anlamı $\mathrm{F}$ testiyle kontrol edildi. Cevap yüzeyi 2. Dereceden eşitlik için varyans analizi (ANOVA) Tablo 5‘de verilmiştir.

Model için F değeri 273,75 olarak bulunmuştur. Model F değerinden ve probabilite değerininin küçük olmasından modelin uyumlu olduğu anlaşılmaktadır. Mikroorganizma derişiminin model tarafından öngörülmesi için $\mathrm{R}^{2}, \mathrm{R}_{\text {Adj }}^{2}, \mathrm{R}_{\text {Pred }}^{2}$ ve $\mathrm{R}$ değerlerinin 1 'e çok yakın olması deneysel değerlerle model 


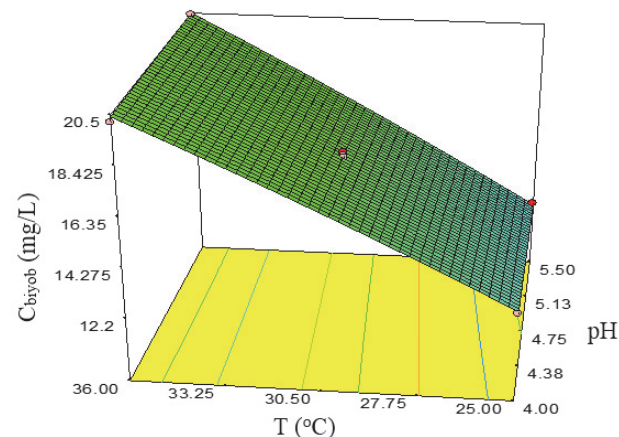

(a)

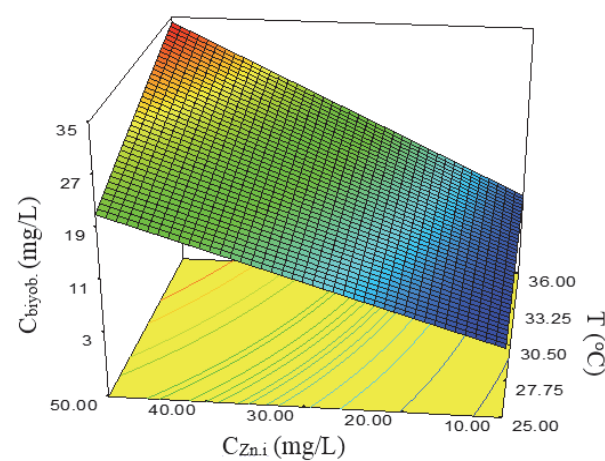

(b)

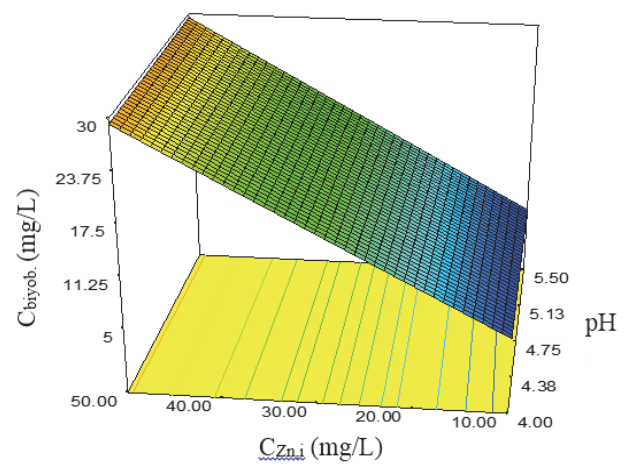

(c)

Şekil 2-(a) CYY ile, Zn(II) biyobirikiminin sıcaklık ve pH ile değişimini gösteren üç boyutlu grafiği, (b) CYY ile, $\mathrm{Zn}(\mathrm{II})$ biyobirikiminin sıcaklık ve $\mathrm{C}_{\mathrm{Zn,i}}$ ile değişimini gösteren üç boyutlu grafiği, (c) CYY ile, $\mathrm{Zn}(\mathrm{II})$ biyobirikiminin $\mathrm{pH}$ ve $\mathrm{C}_{\mathrm{Zn}, \mathrm{i}}$ ile değişimini gösteren üç boyutlu grafiği (Figure 2-(a) Response surface plot described by the model which represents the effect of $\mathrm{pH}$ and temperature and their mutual effects on $\mathrm{Zn}$ (II) bioaccumulating (b) Response surface plot described by the model which represents the effect of $\mathrm{C}_{\mathrm{Zn}, \mathrm{i}}$ and temperature and their mutual effects on $\mathrm{Zn}$ (II) bioaccumulating (c) Response surface plot described by the model which represents the effect of $\mathrm{C}_{\mathrm{Zn}, \mathrm{i}}$ and $\mathrm{pH}$ and their mutual effects on $\mathrm{Zn}(\mathrm{II})$ bioaccumulating)

Tablo 5. Cevap yüzeyi kuadratik eşitlik için, sıcaklık, $\mathrm{pH}$ ve $\mathrm{C}_{\mathrm{zn}, \mathrm{i}}$ fonksiyonu olarak $R$. delemar üremesinin varyans analizi (ANNOVA) (Analysis of variance (ANOVA) for the fitted quadratic polynomial model of acid phosphatase activity as a function of concentration levels of medium components)

\begin{tabular}{|c|c|c|c|c|c|c|}
\hline Kaynak & $\begin{array}{l}\text { Kareler } \\
\text { toplamı } \\
\text { (Sum of } \\
\text { squares) }\end{array}$ & DF & $\begin{array}{l}\text { Ortalamanın } \\
\text { Karesi (Mean } \\
\text { square) }\end{array}$ & F- Değeri & $\begin{array}{l}\text { Probobilite } \\
(\mathrm{P})>\mathrm{F}\end{array}$ & \\
\hline Model & 3,20 & 9 & 0,36 & 273,75 & $<0,0001$ & uyumlu \\
\hline $\begin{array}{l}\text { Arta kalan } \\
\text { (Residual) }\end{array}$ & $9,089 \cdot 10^{-3}$ & 7 & $1,29.10^{-3}$ & & & \\
\hline $\begin{array}{l}\text { Uyum eksikliği } \\
\text { (Lack of fit) }\end{array}$ & $9,75 \cdot 10^{-4}$ & 3 & $3,25.10^{-4}$ & 0,16 & 0,9178 & \\
\hline Hata (Pure eror) & $8,11.1^{0-3}$ & 4 & $2,082 \cdot 10^{-3}$ & & & \\
\hline $\begin{array}{l}\text { Düzeltilmiş } \\
\text { toplam }\end{array}$ & 3,21 & 16 & & & & \\
\hline $\mathrm{R}^{2}=0,9972$ & $\mathrm{R}_{\mathrm{Adj}}^{2}=0,9935$ & $\mathrm{R}_{\mathrm{P}_{1}}^{2}$ & $0,9912 \mathrm{R}=0,9$ & & & \\
\hline
\end{tabular}

değerler arasındaki uyumun çok iyi olduğuna işaret eder.

Sicakl1k, pH ve Zn(II) konsantrasyonunun hem birinci dereceden etkisinin hem de ikinci dereceden etkisinin, hem de parametrelerin çoklu etkileşimlerinin, mikroorganizma konsantrasyonu üzerinde önemli olduğu, $0,05^{\prime}$ den daha küçük olasılık değerlerinden anlaşılmaktadır. Şekil 3' de üç boyutlu $\mathrm{pH}$ ve sıcaklığa karşı mikroorganizma cevap yüzeyine ait izdüşüm grafiği görülmektedir. İzdüşüm grafiklerinin şekillerinin dairesel veya eliptik olması, değişkenler arasındaki etkileşimlerin anlamlı olup olmadığına işaret eder. Eğer bağımsız değişkenler arasındaki etkileşimler anlamlı ise şekil 4' de görüldüğü eliptik izdüşüm grafikleri elde edilir. Şekil 4.a ve b' de 


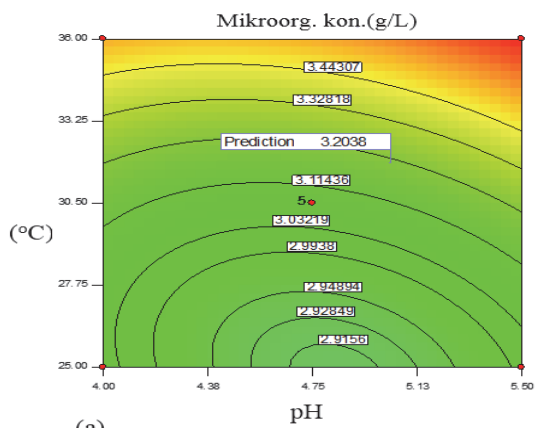

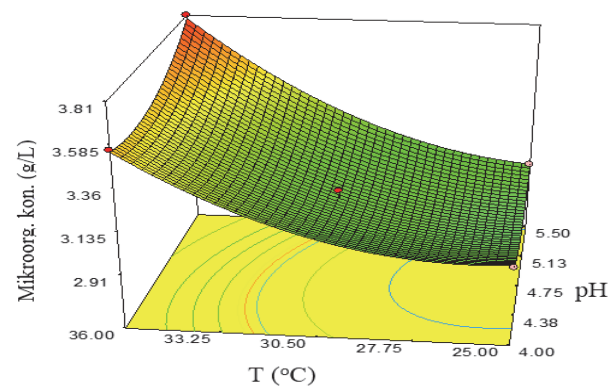

(b)

Şekil 3-(a) CYY ile, mikroorganizma konsantrasyonunun sıcaklık ve pH ile değişimini gösteren kontür grafiği (b) CYY ile, mikroorganizma konsantrasyonunun sıcaklık ve $\mathrm{pH}$ ile değişimini gösteren üç boyutlu grafiği (Figure 3-(a) Response surface contour plot of microorganism concentration showing interactive effect of temperature and pH (b) Response surface plot described by the model which represents the effect of temperature and $\mathrm{pH}$ and their mutual effects on $\mathrm{Zn}$ (II) bioaccumulating)
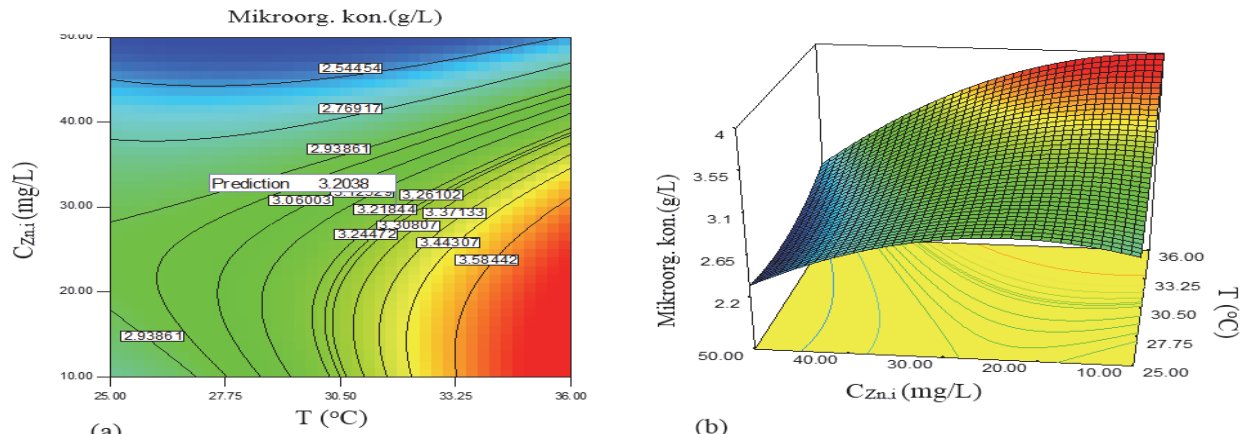

(b)

Şekil 4-(a) CYY ile, mikroorganizma konsantrasyonunun $C_{Z n, i}$ ve sicaklık ile değişimini gösteren kontür grafiği (b) CYY ile, mikroorganizma konsantrasyonunun $\mathrm{C}_{\mathrm{Zn,i}}$ ve sıcaklık ile değişimini gösteren üç boyutlu grafiği (Figure 4-(a) Response surface contour plot of microorganism concentration showing interactive effect of $\mathrm{C}_{\mathrm{Zn}, \mathrm{i}}$ and temperature (b) Response surface plot described by the model which represents the effect of $\mathrm{C}_{\mathrm{Zn}, \mathrm{i}}$ and temperature and their mutual effects on $\mathrm{Zn}$ (II) bioaccumulating)
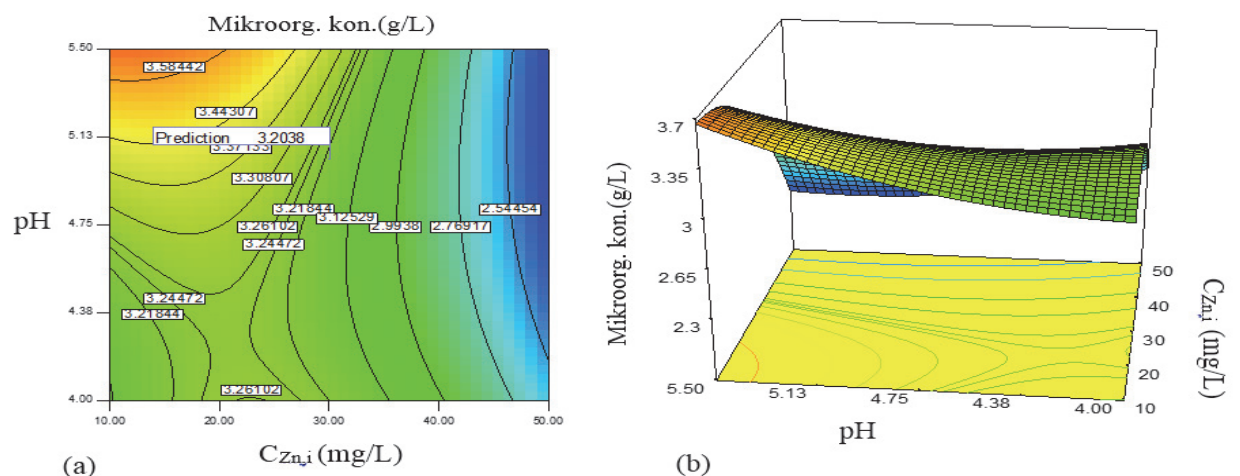

Şekil 5-(a) $C Y Y$ ile, mikroorganizma konsantrasyonunun $\mathrm{C}_{\mathrm{Zn,i}}$ ve $\mathrm{pH}$ ile değişimini gösteren kontür grafiğgi (b) CYY ile, mikroorganizma konsantrasyonunun $\mathrm{C}_{\mathrm{Zn}, \mathrm{i}}$ ve $\mathrm{pH}$ ile değişimini gösteren üç boyutlu grafiği (Figure 5-(a) Response surface contour plot of microorganism concentration showing interactive effect of $\mathrm{C}_{\mathrm{Zn}, \mathrm{i}}$ ve pH (b) Response surface plot described by the model which represents the effect of $\mathrm{C}_{\mathrm{Zn}, \mathrm{i}}$ and $\mathrm{pH}$ and their mutual effects on $\mathrm{Zn}$ (II) bioaccumulating)

mikroorganizma derişiminin sıcaklık arttıkça arttı̆̆ ancak başlangıç $\mathrm{Zn}(\mathrm{II})$ iyon konsantrasyonu arttıkça şiddetle azaldığ 1 görülmektedir. Şekil 5' de çalışılan $\mathrm{pH}$ aralığı boyunca, yüksek başlangıç $\mathrm{Zn}(\mathrm{II})$ iyonu konsantrasyonlarında mikroorganizma konsantrasyonunun düştüğü, düşük başlangıç $\mathrm{Zn}(\mathrm{II})$ iyonu konsantrasyonlarinda $\mathrm{pH}$ 5,03, de mikroorganizma konsantrasyonu için maksimum değerlerinin elde edildiği görülmektedir. Ancak amaç asit fosfataz aktivitesini ve $\mathrm{Zn}(\mathrm{II})$ biyobirikimini maksimize eden uygun aralıktaki mikroorganizma konsantrasyonunu belirlemektir. Grafiklerden de görüldüğü gibi ortam pH' inın 5,03, sıcaklığının 31,82 ${ }^{\circ} \mathrm{C}$ ve başlangıç metal iyonu konsantrasyonunun 30,15 $\mathrm{mg} / \mathrm{L}$ olduğu yerde, $3,2038 \mathrm{~g} / \mathrm{L}$ mikroorganizma konsantrasyonu elde edilmiştir. 


\subsection{Deney doğrulama (Experimental verification)}

CYY ile elde edilen deney sonuçlarını doğrulamak ve deneysel değerlerden sapmayı görebilmek için yapılan deney doğrulama sonuçlarından, asit fosfataz aktivitesi $\quad(\mu \mathrm{mol} / \mathrm{L}-d a k), \quad$ mikroorganizma konsantrasyonu (g/L) ve $\mathrm{Zn}(\mathrm{II})$ biyobirikimi (mg/L) için \% hata değerleri sirasıyla $0,84,5,79$, ve 3,77 olarak bulunmuştur.

\section{SONUÇLAR (RESULTS)}

Design Expert 7,0 kullanılarak Zn(II) için en iyileme deneyleri yapılmış ve asit fosfataz aktivitesi için doğrusal, mikroorganizma konsantrasyonu ve $\mathrm{Zn}$ (II) biyobirikimi için kuadratik eşitliğe tam bir uyum gözlenmiştir. CYY ile yapılan çalışmalar sonucunda $\mathrm{pH} 5,03,31,82^{\circ} \mathrm{C}$ ve $30,15 \mathrm{mg} / \mathrm{L}$ başlangıç değerleri için deneyler tasarlanmış, asit fosfataz aktivitesi 794,098 $\quad \mu \mathrm{mol} / \mathrm{L}-\mathrm{dak}, \quad$ mikroorganizma konsantrasyonu 3,203 g/L ve biyosorplanan $\mathrm{Zn}(\mathrm{II})$ miktarı 17,62 mg/L olarak öngörülmüştür. Deney doğrulama deneyi yapılarak sonuçların duyarlılığı ve geçerliliği gösterilmiştir. $\mathrm{Bu}$ çalışmayla CYY kullanılarak, özellikle tıp ve eczacılık alanında önemli bir yere sahip olan asit fosfataz enziminin en etkin besin ortamı içeriğine ulaşılarak, kısa sürede üretimine katkıda bulunulduğu düşünülmektedir.

\section{KAYNAKLAR (REFERENCES)}

1. Abdallah A.A, Magboul P., L.H. McSweeney. 'Department of food science and techonology', Food chemistry, 6515-6522, 1999.

2. Schmidt G.G. Bartsch. M. C. Lamont. T. Herman. and M. Liss, "Acid phosphatase of baker's yeast: an enzyme of the external cell surface', Biochemistry, 2, 126-121, 1963.

3. Nyc. J.F. 'A repressible acid phosphatase in Neurospora crassa', Biochem. Biophysic, 27, ,183-188, 1967.

4. Blum J. J. 'Observation of the acid phosphatases of Euglena gracilis', J. Cell Biology., 24, 223234, 1956.

5. Tsekova K. and Galabova D. 'Phosphatase production and activity in copper(II) accumulating Rhizopus delemar'. Enzyme Microb. Technology, 33, 926-931, 2003.

6. Leborans G.F. and Novillo. A., "Toxicity and Bioaccumulation of Cadmium Olisthodiscus luteus (Raphidophyceae) Water Resource, 30, 57-62, 1996.

7. Tsezos M. and Volesky B., "Biosorption of Uranium and Thorium". Biotechnology and Bioengineering, 23, 583-604, 1981.

8. Macaskie L.E., Wates J.M., Dean A.C.R.' Cadmium accumulation by a Citrobacter $s p$. immobilized on gel and solid supports: applicability to the treatment of liquid wastes containing heavy metal cations', Biotechnology and Bioengineering, 30, 66-73, 1987.

9. Stat ease, Inc 2021 East Hannepin Ave., Suite 480 Minneapolis, MN 55413 Design Expert version 7.0, Buil date 2005 .

10. Acıkel Ü., Ersan, M., 'Acid phosphatase production by Rhizopus delemar: A role played in the $\mathrm{Ni}$ (II) bioaccumulation process', Journal of Hazardous Materials, 184, 632639, 2010.

11. Durak Z. E, Gürü M., 'Isolation, Inhıbition and Kinetic Modelling of alakline phospatase (Alp) Enzyme'Journal of Faculty of Engineering and Architecture of Gazi University., 28, 1, 2013. 
